\title{
Food matrix: Natural barrier or vehicle for effective delivery of carotenoids from processed foods?
}

\author{
Vassilios Raikos* \\ Rowett Institute, University of Aberdeen, Aberdeen, AB25 2ZD, Scotland, UK
}

\begin{abstract}
Carotenoids are lipophilic compounds naturally occurring in plant species where they exert their main biological role as photosynthetic pigments. Due to their chemical structure, carotenoids have the ability to act as antioxidants primarily by scavenging reactive oxygen species. The antioxidant potential of carotenoids is of significant importance to human health and a carotenoidrich diet is recommended for the prevention of a number of chronic and age-related diseases. The bioaccessibily and bioavailabilty of carotenoids is not proportional to their relative abundance in the original food matrix. The structural integrity of the plant material in which they are embedded and their chemical interactions with other food components seem to be critical factors for their release from the food source and their subsequent uptake by cells at the intestinal epithelium. In addition to food microstructure, food processing is also important for carotenoid bioavailabilty. Heat treatment, acidification and exposure to light can induce isomerisation and oxidation of the phytochemical compounds. It is evident that the absorption of carotenoids in a biologically active form is a complex, multi-step process depending on many variables. In this context the aim of this review is to present and critically discuss evidence relating to the association between food processing and carotenoid bioavailability. Emphasis is given on the food matrix composition and the chemical properties of the individual phytochemicals for formulating conclusions on carotenoid availability from processed meals.
\end{abstract}

Keywords: Food matrix, Carotenoids, Processing, Heat treatment, Bioaccessibility.

Accepted on December 05, 2016

\section{Introduction}

Carotenoids are plant secondary metabolites that are involved in photosynthesis, antioxidation and phytohormone synthesis. The subcellular localization of carotenoids in plant organelles (chloroplasts, chromoplasts) provides a stable environment which prevents their release or chemical degradation. On the other hand, compartmentalization within the plant cell is the main physical barrier that hampers carotenoid absorption during digestion in the human gastrointestinal tract [1].

The efficient delivery of carotenoids from diet to target tissues where they may exert various biological functions includes several stages such as: i) the release from the food matrix and the subsequent mixed micelle formation during intestinal digestion, ii) uptake by the enterocytes via passive diffusion, iii) packaging into triacylglycerol-rich chylomicrons and iv) secretion into the lymph system [2-4]. Therefore the disruption of the food matrix and the solubilisation of carotenoids within micelles is a critical step for intestinal absorption of carotenoids.

Fruits and vegetables are prone to physical, enzymatic, chemical and microbial deterioration and as a result have a limited shelf-life. To prolong the shelf life and meet the consumers' demands for products of high nutritional value and sensorial quality, fruits and vegetable are quite commonly processed. Thermal processing for instance (e.g. pasteurization, blanching) is traditionally used to inactivate microorganisms and enzymes and thus prevent quality deterioration due to microbial growth and enzymatic browning. On the other hand, depending on the nature of the product and the intensity of treatment applied, conventional thermal processing may reduce the sensory and nutritional properties of processed foods [5]. For instance some pigments belonging to the carotenoid group are thermolabile and sterilisation or high temperature pasteurization can induce their degradation. To compensate for nutritional losses, novel technologies are frequently applied which offer significant advantages in terms of the physical appearance and nutritional attributes of the end product.

Food processing (mechanical and thermal) is likely to affect the cellular matrix in which phytochemicals are embedded and therefore carotenoid content and bioaccessibility need to be determined for processed food products. A voluminous body of literature describes the effect of food processing on carotenoid structural stability and bioaccessibility and results are often contradictory. This complex relationship may be interpreted in a more mechanistic way by differentiating between the processing methods. To this end, experimental evidence from domestic and industrial food processing is presented which aims to update current knowledge and provide useful insights on carotenoid accessibility and bioavailability from processed food matrices.

\section{Domestic processing}

Handling and storage: Fruits and vegetables are typically classified as "minimally processed" foods. This is because they are often consumed as "fresh" products and undergo minimum processing (washing, peeling and slicing) prior to consumption. During the preparation stages the cellular structures are disrupted and thus one would expect that this type of mechanical processing would facilitate the release 
of carotenoids from their natural environment [6]. On the other hand, chopping or slicing the fruits and vegetables changes the cellular architecture and enzymes (i.e., oxidases) and substrates which are normally compartmentalised may be brought together. This in turn may result in chemical degradation of phytochemicals. A study was recently published which investigated the impact of handling and distribution of guava, mango and papaya fruits on the carotenoid content in a commercial restaurant setting [7]. According to the findings of this study, the levels of $\beta$-carotene, lycopene and $\beta$-cryptoxanthin remained unaffected by the preparation and handling stages for a total period of $4.5 \mathrm{~h}$ (from reception until consumption). This indicates that the nutritional value of fruits containing carotenoids is preserved under the handling conditions (peeling, slicing and refrigeration) typically encountered in a commercial restaurant.

Cooking: Following the preparation stage, fruits and vegetables may be consumed either raw or undergo further processing (i.e., cooking). Domestic cooking usually involves the use of heat treatment which results in structural changes of compounds at subcellular level and is likely to affect carotenoid bioaccessibility. Depending on the type of fruit or vegetable, heating may soften the plant tissue, rupture the cell membrane and denature the carotene-protein complexes resulting in increased carotenoid bioaccessibility [8]. Thus one would expect carotenoids to become more readily available for absorption after cooking as intermolecular bonding forces between the former and the tissue matrix are weakened and as a result their release from the cellular environment is enhanced.

Current literature indicates that heat processing of fruit and vegetables may affect the bioaccessibility of carotenoids depending on: a. the food matrix, b. the intensity and type of the treatment and c. the chemical nature of the phytochemical. Scientific evidence suggests that domestic heat processing is likely to reduce the carotenoid levels in fruits and vegetables. On the other hand, the release from the matrix and subsequent incorporation into micelles, commonly known as bioaccessibility, is likely to increase post-processing. Boiling of chili peppers $\left(100^{\circ} \mathrm{C}\right)$ for a period of $10 \mathrm{~min}$ resulted in significant losses in the content of both $\beta$-carotene and $\beta$-cryptoxanthin [9]. However, the micellar carotenoid content of the processed peppers was similar or even higher compared to the one determined for the fresh samples. Similarly, significant losses on the carotenoid content of spinach leaves during hydrothermal cooking (boiling at $98^{\circ} \mathrm{C}$ for $20 \mathrm{~min}$ ) were reported [10]. Violaxanthin was completely degraded and lutein and $\beta$-carotene contents were decreased by $58 \%$ and $34 \%$ respectively. In agreement with the previous study, the bioaccesibility of lutein and $\beta$-carotene was significantly increased (15-fold and 72-fold, respectively) after boiling indicating the beneficial role of cooking on the solubilisation of carotenoids into micelles. Furthermore, the cooking conditions may also determine the carotenoid retention and bioaccessibility during domestic processing [11]. Heating method and temperature, pressure, the presence of oxygen and the contact of cooking media (i.e., water) with the vegetables seem to impact on the cell structure and subsequently affect the release of carotenoids from the food matrix. Recent studies indicated that $\beta$-carotene is more readily available from traditionally cooked (boiled) carrots or cook-vide compared with sous-vide [12]. Sous-vide cooking of carrots preserved the vegetable organelles and resulted in lower extractability of $\beta$-carotene. However, these results contradict the findings of other studies which clearly suggest that sous-vide cooking of carrots is a better method for processing the vegetables in a domestic setting compared to boiling [13]. This was attributed to the mild heating conditions $\left(<100^{\circ} \mathrm{C}\right)$ used for sous-vide cooked carrots which helped minimise nutrient losses.

A considerable number of studies indicate that carotenoid degradation during thermal processing is species-specific. Domestic heat-processing such as boiling induced carotenoidspecific degradation in native Andean potatoes accessions [14]. Boiling significantly reduced the contents of violaxanthin and antheroxanthin but lutein and zeaxanthin levels remained unaffected or even increased post-processing. This indicates that the amount of carotenoids available for ingestion from plant sources is influenced not only by the food processing conditions but also depends on the species of carotenoids present in the food matrix. A recently published study suggests that the type of carotenoid largely determined bioaccessibility of the bioactive compounds upon thermal processing and may be more important than the type of food matrix [15]. According to the findings of this study, incorporation into micelles following thermal treatment of atomic red carrots was higher for $\beta$-carotene compared to lycopene within the same matrix. It was hypothesised that lycopene's sub-localisation and interactions with other components during thermal processing led to physical entrapment which limited its bioaccessibility. Other studies indicate that carotenoids with pro-vitamin A activity are more heat-tolerant compared to xanthophylls [16]. There was a significant decrease in violaxanthin and lutein content following steam processing of pumpkin puree at $100^{\circ} \mathrm{C}$ for $10 \mathrm{~min}$. On the other hand, carotenes such as $\zeta$-carotene were moderately affected (23\% decrease) and overall the major carotenoids with pro-vitamin A activity ( $\alpha$-carotene, trans- $\beta$-carotene) were recovered at high rates $(>75 \%)$ post-processing.

Finally, the type of heat treatment and more specifically the rate of heating seem to be critical with respect to the effect on carotenoid stability. Degradation of carotenoids in extra virgin olive oil initiated at $140^{\circ} \mathrm{C}$ for the conventional heating process (heater plate under stirring conditions). The same effect on carotenoid structure was observed at $180^{\circ} \mathrm{C}$ when a microwave heating process was adopted [17]. The temperaturedependent carotenoid degradation observed in this study was attributed to the different heating rates achieved by the two heating processes. Microwave (at high powers) is heating faster and more uniformly the food which results in less profound degradation of the bioactive components.

\section{Industrial processing}

High-pressure processing: High-pressure processing (HPP) is an emerging food preservation technology based on the application of pressures between 200 and $900 \mathrm{MPa}$ to inactivate food-borne microorganisms and enzymes [18]. Current research indicates that HPP is as effective as conventional heat pasteurization for maintaining the microbial stability of nectarine purée during a long refrigerated storage period [19]. Furthermore, HPP affected less the organoleptic properties (colour) of the product compared to the thermally treated purée and even intense $\mathrm{HP}$ treatment $\left(600 \mathrm{MPa}, 10 \mathrm{~min}, 10^{\circ} \mathrm{C}\right)$ did not 
have a noticeable impact on the carotenoid content. The lowest $\mathrm{HP}$ intensity $\left(450 \mathrm{MPa}, 5 \mathrm{~min}, 10^{\circ} \mathrm{C}\right)$ applied in this study resulted in an increase in the extraction yield of carotenoids indicating that carotenoids are pressure stable and HPP may present advantages compared to the thermal treatment. Further evidence regarding the application of HPP on a different food matrix (fruit juice-milk beverage) was published recently [20]. Although HPP treatment (400 $\mathrm{MPa}, 5 \mathrm{~min}, 40^{\circ} \mathrm{C}$ ) and thermal treatment $\left(90^{\circ} \mathrm{C}, 30 \mathrm{~s}\right)$ exerted no significant influence on the majority of the individual carotenoids content, a decrease in carotenoid bioaccessibility was observed for both methods of processing. However, bioaccessibility losses were higher for pasteurised samples indicating that HPP can be applied to minimise nutritional losses due to processing effects. Recently published studies also confirm the ability of carotenoids to withstand HPP even when more intensive treatments are applied [21]. The carotenoid content of red (carrot, tomato, red pepper) and green (broccoli, green pepper, spinach) vegetables was not significantly affected by High Pressure (625 MPa, $5 \mathrm{~min}, 20^{\circ} \mathrm{C}$ ) and High Pressure High Temperrature $\left(625 \mathrm{MPa}, 5 \mathrm{~min}, 70^{\circ} \mathrm{C}\right.$ and $117^{\circ} \mathrm{C}$ ) processing. In some cases extractability increased (lutein and $\beta$-carotene for broccoli and spinach, respectively) whereas at the highest temperature tested $\left(117^{\circ} \mathrm{C}\right)$ some carotenoid degradation was also observed ( $\beta$-carotene and lutein for red and green pepper, respectively). Although the implementation of this novel technology appears to be promising for the food industry, optimal conditions need to be identified for individual food matrices and more importantly the complex relationship between HPP and carotenoid bioaccessibility requires further investigation.

\section{Pulsed Electric Field}

Pulsed electric field (PEF) technology involves the application of high voltage (typically $20-80 \mathrm{kV} / \mathrm{cm}$ ) to foods placed between two electrodes. PEF treatment is commonly applied at ambient temperature for less than $1 \mathrm{~s}$ and is considered superior to traditional heat treatment as any unwanted sensoryrelated changes of foods are greatly reduced. The effect of such a treatment on the carotenoid content of various food matrices has been widely investigated. The effect of high intensity pulsed electric fields $(35 \mathrm{Kv} / \mathrm{cm}$ with $4 \mu$ s bipolar pulses at $200 \mathrm{~Hz}$ for 800 or $1400 \mu \mathrm{s}$ ) and thermal treatment $\left(90^{\circ} \mathrm{C}, 60 \mathrm{~s}\right)$ on a fruit juice-soymilk beverage stored at $4^{\circ} \mathrm{C}$ was recently documented [22]. According to the findings of this study both treatments lead to a significant decrease of the carotenoid content which was particularly profound for lutein, zeaxanthin and $\beta$-cryptoxanthin. On the positive side, carotenoid degradation was lower for beverages treated with PEF (9.8-18.4\%) compared to the samples that were heattreated $(25.9 \%)$. Other studies indicate that PEF treatment may enhance the generation of secondary plant metabolites by inducing stress reactions [23]. Initially moderate PUF treatment $(1 \mathrm{KV} / \mathrm{cm}$ with 16 monopolar pulses of $4 \mu \mathrm{s}$ at $0.1 \mathrm{~Hz}$ ) was applied to raw tomatoes. Treated and untreated tomatoes were refrigerated for $24 \mathrm{~h}$ and were then used to produce juices which were either heat treated $\left(90^{\circ} \mathrm{C}, 60 \mathrm{~s}\right)$ or subjected to high-intensity PUF $(35 \mathrm{Kv} / \mathrm{cm}$ with $4 \mu$ s bipolar pulses at 100 $\mathrm{Hz}$ for $1500 \mu \mathrm{s})$. Results indicated that PUF increased the content of lutein and $\alpha$ - and $\beta$-carotene in juices compared to the juices made of untreated tomatoes. The authors suggested that PUF treatment may activate the expression of enzymes such as $\beta$-cyclase and $\varepsilon$-cyclase which are implicated in carotenoid synthesis. Furthermore, increased $\alpha$-carotene levels and the formation of cis-lycopene isomers were documented [24] for tomato samples subjected to moderate PUF treatment (0.4-2 KV/cm with 5-30 monopolar pulses of $4 \mu \mathrm{s}$ at $0.1 \mathrm{~Hz}$ ). PUF treatment results in tissue disruption which in turn may promote gene expression related to carotenoid biosynthesis. The activation of enzymes involved directly in carotenoid biosynthesis in plants such as phytoene synthase and $\zeta$-carotene desaturase may at least partially explain the metabolic activity of the PUF-treated tomato fruits observed in this study. Finally PUF treatment may also be combined with other processing methods (i.e., blanching) for enhancing release of carotenoids from the food matrix and increasing bioaccessibility by a synergistic mechanism [25].

\section{High Pressure Homogenisation}

High pressure homogenisation (HPH) is extensively used during food processing to increase the physical stability of various products. The samples are forced through a narrow gap in the homogenising valve where conditions of high turbulence and shear combined with compression, acceleration, pressure drop and impact are created. As a consequence, the sample structure is altered by cell disruption resulting in a homogeneous and uniform product with improved texture and increased shelf-life. Recent studies [26] describe the effect of HPH on the microstructure and bio accessibility of carotenoids from tomato pulps. Although the food matrix was disrupted by HPH and tomato pulp consistency improved, in vitro bio accessibility of all carotenoids was reduced. This was attributed to the breakdown of the tomato cell aggregate structure and the formation of a strong fibre network following homogenisation which entrapped carotenoids and rendered them less available for digestive enzymes and bile salts. Furthermore, thermal treatment $\left(90^{\circ} \mathrm{C}, 30 \mathrm{~min}\right)$ of $\mathrm{HPH}$-treated tomato pulps did not improve the in vitro bio accessibility of lycopene which further confirmed the inverse relationship between HPH and carotenoid bio accessibility [27]. However, lycopene incorporation into micelles was enhanced resulting in significantly higher bio accessibility when HPH-tomato pulp was subjected to microwave heating $\left(90^{\circ} \mathrm{C}\right)$ in the presence of lipids [28]. Both mechanical and thermal processing is required to efficiently remove the physical barriers of the tomato cellular structure and release lycopene from the fibrous structure formed. Although the presence of lipids (5\%) clearly improved the bio accessibility of lycopene, the type of lipid was of minor importance compared to the process conditions applied. Finally, the effectiveness of HPH on the in vitro bio accessibility of carotenoids depends also on the food source and the carotenoid species. Previous research [29] demonstrated that HPH may be applied to carrot emulsions to increase the release and micellar incorporation of $\alpha$ - and $\beta$-carotene (1.5 to 1.6 fold). However, in vitro bio accessibility of lycopene for HPH-treated tomato emulsions was not improved, due to the formation of fibrous cell structures which restrained its accessibility. Thus the intactness of the cell wall structure and the degree of cellular disruption achieved post-processing largely determine the bio accessibility of the individual carotenoids. 
Table 1. Modern processing technologies.

\begin{tabular}{|c|c|c|c|c|}
\hline $\begin{array}{c}\text { Type of } \\
\text { processing }\end{array}$ & Principle of operation & Applications & Effect on carotenoids & References \\
\hline $\begin{array}{l}\text { High pressure } \\
\text { processing }\end{array}$ & $\begin{array}{l}\text { A non-thermal, cold processing technique } \\
\text { in which the food in its final packaging is } \\
\text { subjected to hydrostatic pressure inactivating } \\
\text { its microorganisms and extending the shelf life } \\
\text { of the product }\end{array}$ & $\begin{array}{l}\text { Meat, seafood, } \\
\text { dairy products, } \\
\text { juices, fruits, dips } \\
\text { and sauces }\end{array}$ & $\begin{array}{l}\text { Bioaccessibility of fruit-milk beverages } \downarrow \\
\text { Overall carotenoid content of vegetables } \uparrow \\
\text { HPP is nutritionally advantageous compared to thermal } \\
\text { processing and carotenoid extractability may be } \\
\text { improved if optimum conditions are identified }\end{array}$ & [16-18] \\
\hline $\begin{array}{l}\text { Pulsed electric } \\
\text { fields: }\end{array}$ & $\begin{array}{l}\text { A non-thermal method in which food is } \\
\text { subjected to bursts of electricity that causes } \\
\text { microbial inactivation with minimum or no } \\
\text { detrimental effect on sensory quality attributes }\end{array}$ & $\begin{array}{l}\text { Liquid and semi- } \\
\text { liquid foods (milk, } \\
\text { soups, yoghurt, } \\
\text { juices, liquid } \\
\text { eggs) }\end{array}$ & $\begin{array}{l}\text { Carotenoid content of fruit-soymilk juice } \downarrow \\
\text { Carotenoid content of tomato products } \uparrow \\
\text { The effect of PUF on the carotenoid content depends } \\
\text { on the treatment intensity and the properties of the food } \\
\text { matrix }\end{array}$ & [19-21] \\
\hline $\begin{array}{c}\text { High pressure } \\
\text { homogenisation: }\end{array}$ & $\begin{array}{l}\text { A process in which food is forced through } \\
\text { a special homogenising valve at very high } \\
\text { pressure for reducing and standardizing } \\
\text { the particle size in order to produce a } \\
\text { homogeneous product with improved shelf life, } \\
\text { texture and taste }\end{array}$ & $\begin{array}{l}\text { Liquid foods } \\
\text { (fruit juices, } \\
\text { beverages, } \\
\text { sauces, milk, } \\
\text { baby foods, ice } \\
\text { cream) }\end{array}$ & $\begin{array}{l}\text { Bioaccessibility of tomato products } \downarrow \\
\text { Bioaccessibility of carrot emulsions } \uparrow \\
\text { The effect of HPH on carotenoid bioaccessibility } \\
\text { depends on the carotenoid species and the fibrous } \\
\text { network formed after processing }\end{array}$ & [22-24] \\
\hline Freeze-drying: & $\begin{array}{l}\text { A drying process for preserving heat sensitive } \\
\text { foods in which the water and/or the suspension } \\
\text { medium is crystallized at a low temperature } \\
\text { and thereafter sublimated from the solid state } \\
\text { directly into the vapour phase }\end{array}$ & $\begin{array}{l}\text { Vegetables, } \\
\text { fruits, coffee, } \\
\text { juices, meat, fish }\end{array}$ & $\begin{array}{l}\text { Carotenoid content of fruits and vegetables } \downarrow \\
\text { Freezing at }-20^{\circ} \mathrm{C} \text { seems to be a more advantageous } \\
\text { method of preservation compared to lyophilisation }\end{array}$ & [25-27] \\
\hline
\end{tabular}

\section{Freezing/Freeze-Drying}

Seasonal fruits and vegetables are quite commonly subjected to processing in order to be transported or stored for a certain period of time. This type of processing aims to prolong the shelf-life of products which normally are available for a short, seasonal period. Freeze-drying, formerly known as lyophilisation, is a common preservation method applied to most fruits and vegetables. During lyophilisation samples are dehydrated by freezing the immobilised water into ice and then removing the ice crystals via sublimation into vapour. Recent experimental evidence indicates that the process of lyophilisation results in significant losses of carotenoids when applied to summer fruits and vegetables [30]. The carotenoid degradation was higher compared to frozen commodities $\left(-20^{\circ} \mathrm{C}\right)$ and was attributed to the rapid oxidation of phytochemicals due to the large surface area exposed during processing. Other studies also document significant losses of carotenoids following lyophilisation of red and yellow tomatoes [31]. Lyophilised samples contained significant lower amounts of $\beta$-carotene (14\% and $11 \%$ for red and yellow tomatoes respectively) and lycopene (47\% for red tomatoes) compared to fresh material. During the process of lyophilisation the sample porosity changes significantly which could contribute to carotenoid degradation due to exposure to large amounts of oxygen. No significant differences in the carotenoid content of orange, cherry, apple and kale were observed when stored at $-20^{\circ} \mathrm{C}$ and $-70^{\circ} \mathrm{C}$ [32]. These conditions seem to confer protection against carotenoid degradation compared to lyophilisation and freezing at $-20^{\circ} \mathrm{C}$ appears to be both nutritionally and economically advantageous for preserving fruits and vegetables. Most carotenoids studied ( $\alpha$-carotene, $\beta$-cryptoxanthin, lutein and zeaxanthin) were stable for at least 5 months when preserved under the above storage conditions.

\section{Conclusion}

Domestic processing of fruits and vegetables is likely to reduce the overall carotenoid content and xanthophylls appear to be particularly susceptible to thermal degradation. On the other hand, micellar incorporation and isomerisation of the carotenoids is favoured from conventional household processing resulting in increased bioaccesibility. Food processing may be effectively used to extend the shelf-life and improve the sensory qualities of diverse food products. Evidence suggests that modern processing technologies may have beneficial or undesirable effects on carotenoids in processed foods (Table 1). This largely depends on the type of food processing, the intensity of treatment and the properties of the food matrix. The later include the density of individual carotenoid species, their relative spatial arrangements and any chemical interactions with other food components. It is evident that the choice of processing conditions has a large impact on the in vitro bio accessibility of carotenoids and that this is related to microstructural properties of the food matrix. Processes should thus be optimized in order to deliver products with improved qualities both from a nutritional and a structural perspective.

\section{Acknowledgement}

Funds for the study were provided by the Scottish Government's Rural and Environment Science and Analytical Services Division (RESAS) and conducted as part of the Scottish Government Strategic Research programme.

\section{References}

1. Jeffery J, Holzenburg A, King S. Physical barriers to carotenoid bioaccesibility ultrastructure survey of chromoplast and cell wall morphology in nine carotenoidcontaining fruits and vegetables. J Sci Food Agric. 2012;92:2594-2602.

2. Yeum KJ, Russell RM. Carotenoid bioavailability and bioconversion. Annu Rev Nutr. 2002;22:483-504.

3. Aherne SA, Jiwan MA, Daly T, et al. Geographical location has greater impact on carotenoid content and bioaccessibility from tomatoes than variety. Plant Food Hum Nutr. 2009;64:250-266.

4. Failla ML, Thakkar SK, Kim JY. In vitro bioaccessibility of beta-carotene in orange fleshed sweet potato (Ipomoea batatas Lam.). J Agric Food Chem. 2009;57:10922-10927. 
5. Woolbang CM, Fritos JL, Treeby MT. The effect of high pressure processing on nutritional value and quality attributes of Cucumis melo L. Innov Food Sci Emerg Tech. 2008;9:196-200.

6. Van Buggenhout S, Alminger M, Lemmens L, et al. In vitro approaches to estimate the effect of food processing on carotenoid bioavailability need through understanding of process induced microstructural changes. Trends Food Sci Tech. 2010;21:607-618.

7. Oliveira DdaS, Lobato AL, Ribeiro SM, et al. Carotenoids and vitamin $\mathrm{C}$ during handling and distribution of Guava (Psidium guajava L.), Mango (Mangifera indica L.) and Papaya (Carica papaya L.) at commercial restaurants. J Agric Food Chem. 2010;58:6166-6172.

8. Veda S, Kamath A, Platel K, et al. Determination of bioaccessibility of beta-carotene in vegetables by in vitro methods. Mol Nutr Food Res. 2006;50:1047-1052.

9. Pugliese A, Loizzo MR, Tundis R, et al. The effect of domestic processing on the content and bioaccessibility of carotenoids from chili peppers (Capsicum species). Food Chem. 2013;141:2606-2613.

10. Courraud J, Berger J, Cristol JP, et al. Stability and bioaccessibility of different forms of carotenoids and vitamin A during in vitro digestion. Food Chem. 2013;136:871-877.

11. Ribeiro EMG, Chitchumroonchokchai C, de Carvalho LMJ, et al. Effect of style of home cooking on retention and bioaccessibility of pro-vitamin A carotenoids in biofortified pumpkin (Cucurbita moschate Duc.). Food Res Int. 2015;77:620-626.

12. Iborra-Bernad C, García-Segovia P, Martínez-Monzó J. Physico-chemical and structural characteristics of vegetables cooked under sous-vide, cook-vide and conventional boiling. J Food Sci. 2015;80:E1725-E1734.

13. Guillén S, Mir-Bel J, Oria R, et al. Influence of cooking conditions on organoleptic and health-related properties of artichokes, green beans, broccoli and carrots. Food Chem. 2017;209-216

14. Burgos G, Amoros W, Salas E, et al. Carotenoid concentrations of native Andean potatoes as affected by cooking. Food Chem 2012;133:1131-1137.

15. Palmero P, Lemmens L, Hendrickx M, et al. Role of carotenoid type on the effect of thermal processing on bioaccessibility. Food Chem. 2014;157:275-282.

16. Provesi JG, Dias CO, Amante ER. Changes in carotenoids during processing and storage of pumpkin puree. Food Chem 2011; 128: 195-202.

17. El-Abassy RM, Donfack P, Materny A. Assessment of conventional and microwave heating induced degradation of carotenoids in olive oil by VIS Raman spectroscopy and classical methods. Food Res Int. 2010;43:694-700.

18. Bayindirli A, Alpas H, Bozoglu F, et al. Efficiency of high pressure treatment on inactivation of pathogenic microorganisms and enzymes in apple orange apricot and sour cherry juices. Food Control. 2006;17:52-58.

19. García-Parra J, González-Cebrino F, Delgado J, et al. Effect of thermal and high-pressure processing on the nutritional value and quality attributes of a nectarine purée with industrial origin during the refrigerated storage. J Food Sci. 2011;76:C618-C625.

20. Cilla A, Alegría A, de Ancos B, et al. Bioaccessibility of tocopherols, carotenoids and ascorbic acid from milk- and soy-based fruit beverages: influence of food matrix and processing. J Agric Food Chem. 2012;60:7282-7290.

21. Sánchez C, Baranda AB, Martínez de Marañón I. The effect of high pressure and high temperature processing on carotenoids and chlorophylls content in some vegetables. Food Chem. 2014;163;37-45.

22. Morales-de la Peña M, Salvia-Trujillo L, Rojas-Graü MA, et al. Changes on phenolic and carotenoid composition of high intensity pulsed electric field and thermally treated fruit juice-soymilk beverages during refrigerated storage. Food Chem. 2011;129:982-990.

23. Vallverdú-Queralt A, Odriozola-Serrano I, Oms-Oliu G, et al. Impact of high-intensity pulsed electric fields on carotenoids profile of tomato juice made of moderateintensity pulsed electric field-treated tomatoes. Food Chem. 2013;141:3131-3138

24. Vallverdú-Queralt A, Oms-Oliu G, Odriozola-Serrano I, et al. Metabolite profiling of phenolic and carotenoid contents in tomatoes after moderate-intensity pulsed electric field treatments. Food Chem. 2013;136:199-205.

25. Jayathunge KGLR, Stratakos Ach, Cregenzán-Albertia $\mathrm{O}$, et al. Enhancing the lycopene in vitro bioaccessibility of tomato juice synergistically applying thermal and non-thermal processing technologies. Food Chem. 2017:221:698-705.

26. Panozzo A, Lemmens L, Van Loey A, et al. Microstructure and bioaccessibility of different carotenoid species as affected by high pressure homogenisation: A case study on differently coloured tomatoes. Food Chem. 2013;141:4094-4100.

27. Colle I, Van Buggenhout S, Van Loey A, et al. High pressure homogenisation followed by thermal processing of tomato pulp: Influence on microstructure and lycopene in vitro bioaccessibility. Food Res Int. 2010;43:2193-2200.

28. Colle IJP, Lemmens L, Van Buggenhout S, et al. Processing tomato pulp in the presence of lipids: The impact on lycopene bioaccessibility. Food Res Int. 2013;51:232-238.

29. Svelander CA, Lopez-Sanchez P, Pudney PDA, et al. High pressure homogenisation increases the in vitro bioaccessibility of $\alpha$ - and $\beta$-carotene in carrot emulsions but not of lycopene in tomato emulsions. J Food Sci. 2011;76:H215-H225.

30. Leong SY, Oey I. Effects of processing on anthocyanins, carotenoids and vitamin $\mathrm{C}$ in summer fruits and vegetables. Food Chem 2012; 133: 1577-1587. 
31. Georgé S, Tourniaire F, Gautier H, et al. Changes in the contents of carotenoids, phenolic compounds and vitamin $\mathrm{C}$ during technical processing and lyophilisation of red and yellow tomatoes. Food Chem. 2011;124:1603-1611.
32. Graça Dias M, Filomena GFC, Camões $M$, et al. Carotenoid stability in fruits, vegetables and working standards - Effect of storage temperature and time. Food Chem. 2014;156:37-41.

\section{*Correspondence to:}

Vassilios Raikos

Metabolic Health, Rowett Institute

University of Aberdeen, Aberdeen, AB25 2ZD

Scotland

UK

Tel: +44 (0) 1224438581

Fax: +44 (0)1224 438699

E-mail: v.raikos@abdn.ac.uk 